\title{
Tumorigenicity of MCF-7 human breast cancer cells lacking the p38 $\alpha$ mitogen-activated protein kinase
}

\author{
Rhone A Mendoza, Emily E Moody, Marlene I Enriquez, Sylvia M Mejia and Gudmundur Thordarson \\ Department of Biomedical Sciences, Paul L. Foster School of Medicine, Center of Excellence in Cancer Research, Texas Tech University Health Sciences Center, \\ 5001 El Paso Drive, El Paso, Texas 79905, USA \\ (Correspondence should be addressed to G Thordarson who is now at Department of Biological Sciences, University of Texas at El Paso, El Paso, Texas 79968, \\ USA; Email: gthordarson2@utep.edu)
}

\begin{abstract}
We have generated cell lines with significantly reduced expression of the $\mathrm{p} 38$ mitogen-activated protein kinase (p38 MAPK), Min-p38 MAPK cells, and used these cells to investigate $\mathrm{p} 38$ MAPK's role in tumorigenesis of breast cancer cells. MCF-7 cells were stably transfected with a plasmid producing small interfering RNA that inhibited the expression of p38 MAPK. Control cells were stably transfected with the same plasmid producing non-interfering RNA. The reduction in the p38 MAPK activity caused a significant increase in the expressions of estrogen receptor- $\alpha$ $(\mathrm{ER} \alpha)$ and the progesterone receptor, but eliminated the expression of ER $\beta$. Min-p38 MAPK cells showed an enhanced overall growth response to $17 \beta$-estradiol $\left(\mathrm{E}_{2}\right)$, whereas GH plus epidermal growth factor were largely ineffective growth stimulators in these cells compared to
\end{abstract}

controls. Although the long-term net growth rate of the Min-p38 MAPK cells was increased in response to $E_{2}$, their proliferation rate was lower compared to controls in short-term cultures. However, the Min-p38 MAPK cells did show a significant decreased rate of apoptosis after $E_{2}$ treatment and a reduction in the basal phosphorylation of p53 tumor suppressor protein compared to controls. When the Min-p38 MAPK cells were xenografted into $E_{2}$-treated athymic nude mice, their tumorigenicity was enhanced compared to control cells. Increased tumorigenicity of Min-p38 MAPK cells was caused mainly by a decrease in the apoptosis rate indicating that the lack of the p38 MAPK caused an imbalance to increase the $\operatorname{ER} \alpha: \operatorname{ER} \beta$ ratio and a reduction in the activity of the p53 tumor suppressor protein. Journal of Endocrinology (2011) 208, 11-19

\section{Introduction}

Estrogen and insulin-like growth factor 1 (IGF-I) are both central to breast development (Kleinberg \& Ruan 2008), and evidence indicates that both these hormones affect carcinogenesis of the breast (Fagan \& Yee 2008). Although both of these hormones are most commonly associated with cell growth stimulation and anti-apoptosis, they will also induce apoptosis under certain conditions. For example, a domain in the C-terminus of the IGF-I receptor (IGF-IR) has been found to have an apoptotic activity (Liu et al. 1998), and apoptotic activity of estrogen under certain physiological circumstances is now well documented (reviewed in Song \& Santen (2003)). However, although we know that estrogen and IGF-I interact closely to regulate mammary gland development, many aspects of these interactions are not well understood. We recently showed (Mendoza et al. 2011) that lowering the expression of IGF-IR caused a decrease in the expression of the estrogen receptor- $\alpha(E R \alpha)$, increased expression of ER $\beta$, and significantly enhanced the apoptosis rate of breast cancer cells. Furthermore, we demonstrated that when the cells with low expression of the IGF-IR were treated with $17 \beta$-estradiol
$\left(\mathrm{E}_{2}\right)$, a rapid (within $15 \mathrm{~min}$ ) increase in activation of the $\mathrm{p} 38$ mitogen-activated protein kinase (p38 MAPK) was seen when compared to controls with intact IGF-IR expression. These results indicate that the reduced level of the IGF-IR caused a shift towards lowering the ER $\alpha: \operatorname{ER} \beta$ ratio. The hypothesis that the ratio of the two ERs might be important for function is not new. Hall \& McDonnell (1999) proposed some 10 years ago that relative levels of the two ERs determined the transcriptional activity of the ERs with ER $\beta$ playing a modulatory role on ER $\alpha$ activity under conditions of limited concentration of the ligand. More recently, Chang et al. (2006) demonstrated the modulatory role of $\operatorname{ER} \beta$ on $\operatorname{ER} \alpha$ transcriptional activity in breast cancer cells. Less is known about the interactions of the two ERs at the plasma membrane to induce non-genomic, rapid action. However, both ER $\alpha$ and $\operatorname{ER} \beta$ are capable of exerting non-genomic activity (Razandi et al. 1999, 2004, Pedram et al. 2006), and they appear to be acting through different signaling pathways and elicit opposite affects, with $\mathrm{ER} \alpha$ activating the extracellular signal-regulated kinase pathway possibly in association with IGF-IR-matrix metalloproteinases-heparin-binding epidermal growth factor (EGF) to stimulate growth (Song et al. 2007) 
and ER $\beta$ activating the p38 MAPK to increase apoptosis (Acconcia et al. 2005). As mentioned above, we recently generated breast cancer cell lines with reduced expression of IGF-IR (Mendoza et al. 2011). We found that these cells showed a decreased growth potential when stimulated with hormones, an increase in the expression of $\operatorname{ER} \beta$, while $\operatorname{ER} \alpha$ levels were reduced. Concomitant with these changes was an increase in the rate of apoptosis and elevated phosphorylation of p38 MAPK in response to estrogen treatment. We speculated that the reduced ER $\alpha: \operatorname{ER} \beta$ ratio caused the increase in the p38 MAPK activation upon $\mathrm{E}_{2}$ treatment and an increase in the rate of apoptosis, probably through the p53 tumor suppressor protein. To investigate this further, we have now generated cell lines with impaired expression of the p38 MAPK, and here we investigated the effects of this impairment on tumorigenicity of these breast cancer cells.

\section{Materials and Methods}

\section{Cells}

The MCF-7 human breast cancer cells were obtained from ATCC (Manassas, VA, USA) and maintained at $37^{\circ} \mathrm{C}$ in 90-95\% humidity with $5 \% \mathrm{CO}_{2}$ in phenol red-free DMEM/F12 medium containing 10\% fetal bovine serum (FBS) and $50 \mu \mathrm{g} / \mathrm{ml}$ gentamicin, basic growth medium. For experimentation, the cells were plated in DMEM/F12 without phenol red and containing 10\% FBS. After overnight culture, the medium was changed to serum-free, phenol red-free, DMEM/F12 containing trace elements and cultured for an additional $24 \mathrm{~h}$. The cells were then exposed to different treatments and for varying lengths of time, as indicated in the figure legends.

\section{Stable transfection of MCF-7 cells}

To block or significantly reduce the $\mathrm{p} 38 \alpha$ MAPK expression, custom-made expression vectors capable of generating small double-stranded interfering RNA (siRNA) corresponding to a 21 nucleotide (nt) sequence of the human p38 $\alpha$ MAPK cDNA sequence were obtained from InvivoGen (San Diego, CA, USA). The control vector carried sequence generating non-interfering, 21 nt RNA (InvivoGen). MCF-7 cells were plated onto 6-well plates in DMEM/F12 medium containing $10 \% \mathrm{FBS}$ and $50 \mu \mathrm{g} / \mathrm{ml}$ gentamicin at $\sim 60 \%$ confluency. They were incubated for $24 \mathrm{~h}$, and then the medium was changed to DMEM/F12 without serum and antibiotics. LipofectAMINE PLUS (Invitrogen) was used for the transfection according to the manufacturer's instructions. Approximately $24 \mathrm{~h}$ after the transfection, fresh medium containing $10 \%$ FBS was added, and the cells were incubated for an additional $48 \mathrm{~h}$. At that time, the cells were exposed to medium containing the selectable marker $(5 \mu \mathrm{g} / \mathrm{ml}$ blasticidin, Fisher Scientific, Pittsburgh, PA, USA). Viable cell colonies were localized and isolated with clone rings. These were cultured in medium containing 10\% FBS and blasticidin. The same cloning procedure was used for the control cells that had been transfected with the inactive vector.

\section{Cell number studies}

The changes in the number of the cells lacking functional p38 MAPK (Min-p38 MAPK) were studied in a defined medium. The cells were plated in 24-well culture plates at the density of 50000 cells/well in DMEM/F12 medium containing 10\% FBS and antibiotics and cultured overnight. The cells were then placed in serum-free, phenol red-free medium and cultured for an additional $24 \mathrm{~h}$. At that time, media containing trace elements (MP Biomedicals, Solon, OH, USA) and different treatments were applied. Control cells were cultured in parallel with the Min-p38 MAPK cells using the same treatments and for the same length of time. Each treatment was continued for 6 days, and the media replenished every other day. The net changes in cell numbers were assessed by measuring the total DNA of the cells using the diaminobenzoic acid method (Hinegardner 1971).

\section{5-Bromo-2'-deoxyuridine incorporation}

ELISA assay (Roche Applied Science) based on 5-bromo-2'deoxyuridine $(\mathrm{BrdU})$ uptake was used to measure the shortterm $(18 \mathrm{~h})$ proliferation rate of the cultured cells. For the assay, the cells were plated onto 96-well plates in 10\% FBS and incubated for $24 \mathrm{~h}$. Medium was then changed to serum free, and incubation continued for an additional $24 \mathrm{~h}$ when the cells were exposed to the different treatments. The treatments were continued overnight, and the following morning the media were removed and fresh treatment media containing $10 \mu \mathrm{M} \mathrm{BrdU}$ were applied to the cells and incubation continued for an additional $90 \mathrm{~min}$. The cultures were then terminated, and BrdU incorporation was measured according to the manufacturer's instructions.

\section{Apoptosis assay}

The rate of apoptosis was measured using an ELISA (M30Apoptosense, Peviva, Bromma, Sweden). This assay utilizes a specific antibody that was generated against a neo-epitope on cytokeratin 18 that is exposed after caspase cleavage (Hagg et al. 2002). For the assay, cells were plated onto $96-$ well plates in DMEM/F12 medium containing 10\% FBS and incubated overnight. The cells were then serum-starved for an additional $24 \mathrm{~h}$ and then treated overnight with different hormones. To assess the total number of viable cells at the time each treatment began, replicate wells were treated with $60 \mu \mathrm{M}$ roscovitine, a concentration that has been shown to cause complete cell apoptosis (Schutte et al. 2004). Experiments were terminated by lysing the cells using $10 \% \mathrm{NP}-40$, final concentration $0.5 \%$, and the cell lysate was then diluted and assayed according to the manufacturer's directions. 


\section{Western blotting}

The expression of the p38 MAPK, ER $\alpha, E R \beta$, the progesterone receptor (PR), the total p53 protein level, and cyclin D1 were assessed using western blotting. The cells were plated onto $60 \mathrm{~mm}$ diameter culture dishes in the DMEM/F12 medium containing 10\% FBS at the density of $4 \cdot 0 \times 10^{6}$ cells/dish and incubated overnight. The medium was then changed to serum free, and the incubation was continued for an additional $24 \mathrm{~h}$ when cells were treated with different treatments and cultured for an additional $24 \mathrm{~h}$. The cells were then scraped and lysed, total protein was extracted, and protein concentrations were measured using the BCA assay (Pierce, Rockford, IL, USA). After electrophoresis, the protein was transferred to polyvinylidene fluoride (PVDF) membrane for western analysis using chemiluminescent detection. The ER $\boldsymbol{\alpha}$-specific antibody was from Thermo Fisher Scientific (Fremont, CA, USA), and antibodies to ER $\beta$, PR, p38 MAPK, p53, cyclin D1, and $\beta$-actin were obtained from Santa Cruz Biotechnology (Santa Cruz, CA, USA). Chemiluminescent detections and densitometric quantifications were carried out using Kodak Image Station 2000R (Eastman Kodak Company), and the results for each protein are expressed as a ratio of $\beta$-actin expression. For each quantitative analysis, the results from two cell lines in each group (controls, Min-p38 MAPK) were pooled. The total number of observations is indicated in the figure legends for all western blots.

\section{ELISA assays for measuring phosphorylation of p53}

Phosphorylation level of the tumor suppressor protein p53 was measured using an ELISA (R\&D Systems, Inc., Minneapolis, MN, USA). This assay is specific for detecting the phosphorylation of serine 46 on the p53 tumor suppressor protein. The cells were plated onto $60 \mathrm{~mm}$ diameter culture dishes in DMEM/F12 medium containing 10\% FBS and cultured for $24 \mathrm{~h}$. The cells were then serum starved for an additional $24 \mathrm{~h}$, and then the different treatments were applied followed by $10 \mathrm{~min}$ incubation at $37^{\circ} \mathrm{C}$ when the reaction was stopped by adding $5 \mathrm{ml}$ ice-cold PBS. After washing, the cells were harvested and lysed, and the lysate was assayed according to the manufacturer's instructions. Total protein concentrations (BCA, Pierce) of the cell lysates were used for normalizing the assay results. Results for the phosphorylation of p53 in Min-p38 MAPK cells 1 and 2 were combined for statistical analysis and compared to control cells.

\section{Xenografting of the Min-p38 MAPK and control cells}

The cells were plated onto $75 \mathrm{~cm}^{2}$ culture plates in DMEM/F12 medium containing 10\% FBS and cultured to confluency. The cells were then harvested by scraping, counted, and suspended in Matrigel (BD Biosciences, Bedford, MA, USA) at a density of $1 \times 10^{7}$ cells per $150 \mu 1$. The athymic nude mice were anesthetized and then inoculated with $1 \times 10^{7}$ cells in $150 \mu$ l Matrigel. The animals received two s.c. inoculations, one in each flank, one with Min-p38 MAPK cells and the other with scrambled siRNA vector control cells. The animals were then given s.c. silastic capsule implants (Thordarson et al. 2004) containing $30 \mu \mathrm{g}$ $\mathrm{E}_{2}$. The mice were inspected weekly for detection of tumors, and all new tumors that were detected were measured using calipers, beginning 1 month after inoculation. The animals were terminated 2 months after inoculation; tumors were harvested, weighed, and fixed in 10\% formalin for histology and immunostaining. All care and use of the animals in this study was approved by the Animal Care Committee at Texas Tech University Health Sciences Center.

\section{Histology}

The formalin-fixed tissues were paraffin embedded and sectioned into $5 \mu \mathrm{m}$ sections. The sections were deparaffinized, rehydrated, and then subjected to antigen retrieval using Trilogy (Cell Marque, Rocklin, CA, USA) and pressure cooker procedure. After blocking with 5\% BSA, and avidin and biotin blocking agents, the tissue sections were exposed to

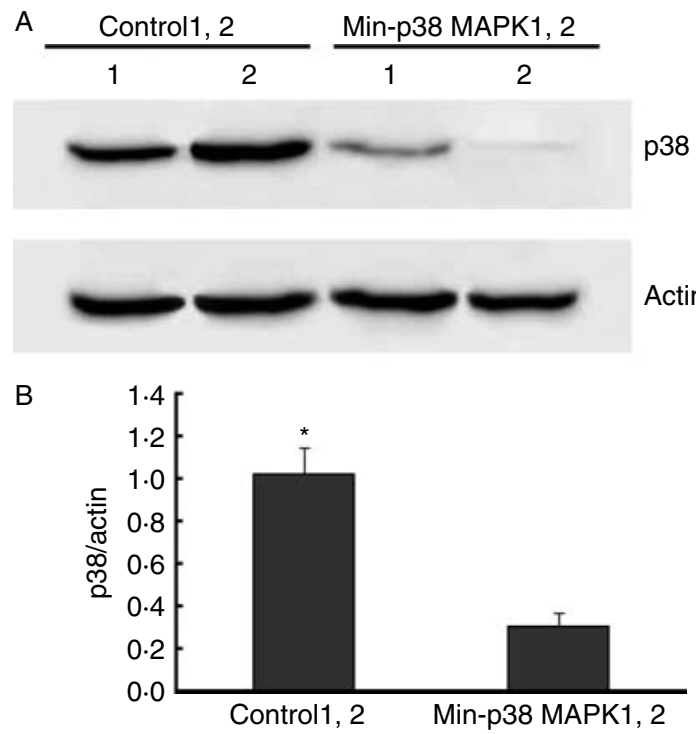

Figure 1 Western blot analysis showing expression of the p38 mitogen-activated protein kinase (p38 MAPK) and $\beta$-actin (internal control) in cloned MCF-7 cells stably transfected with small interfering RNA (siRNA) to the p38 MAPK (Min-p38 MAPK1, 2), and control clones (Control1, 2) transfected with inert small RNA of the same size as the p38 MAPK-siRNA. Cells were plated onto $60 \mathrm{~mm}$ culture dishes in DMEM/F12 medium containing 10\% FBS and cultured for $24 \mathrm{~h}$, followed by serum starvation for an additional $24 \mathrm{~h}$, when cells were harvested and lysed, and total protein was extracted and measured using BCA assay. Samples were electrophoresed using $60 \mu \mathrm{g}$ total protein per lane and western blotted (A). The protein levels of p38 MAPK were quantified using densitometric analysis, and the results are expressed as p38 MAPK/ $\beta$-actin ratio. Each bar represents the mean \pm S.E.M. of four replicates for both groups. Asterisk indicates significant difference between controls and Min-p38 MAPK cells, $P<0 \cdot 05$ (B). 


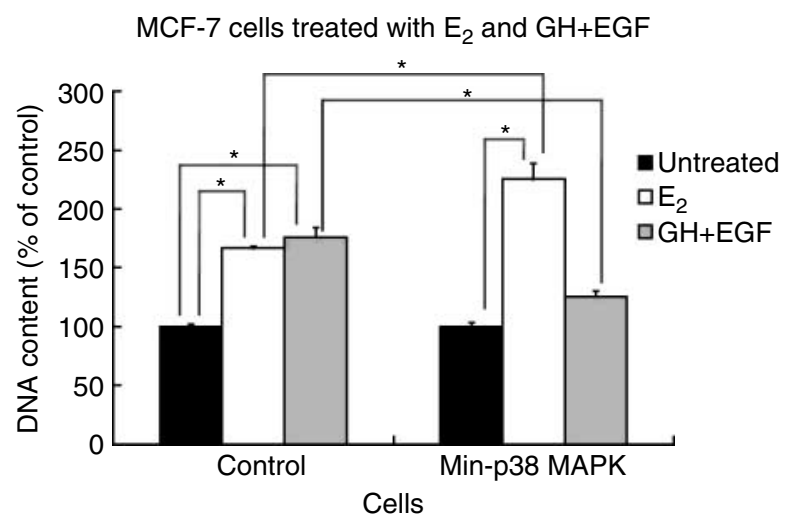

Figure 2 The effects of $100 \mathrm{nM} 17 \beta$-estradiol $\left(\mathrm{E}_{2}\right)$, and a combination of $500 \mathrm{ng} / \mathrm{ml}$ human $\mathrm{GH}$ and $10 \mathrm{ng} / \mathrm{ml}$ epidermal growth factor (EGF) on growth of MCF-7 cells stably transfected with siRNA to the p38 MAPK (Min-p38 MAPK1, 2) and controls with intact expression of p38 MAPK. The cells were plated onto 24-well plates in DMEM/F12 medium containing 10\% FBS and incubated for $24 \mathrm{~h}$, followed by $24 \mathrm{~h}$ serum starvation and then treated for 6 days. Medium was replenished every other day. At the end of the culture period, total DNA was measured to assess overall cell growth. Each bar represents the mean \pm S.E.M. for four replicate wells. *Significantly different, $P<0 \cdot 05$.

primary antibody (p38 $\alpha$ MAPK, Santa Cruz Biotechnology) for $1 \mathrm{~h}$. Immunostaining was detected using Mouse/Rabbit PolyScan HRP/DAB Detection System (Cell Marque).

\section{Statistical analysis}

Data are presented as means \pm s.E.M. of three to eight observations. Significant levels between groups were determined using ANOVA and Student-Newman-Keuls post-hoc test. $P<0 \cdot 05$ was considered statistically significant.

\section{Results}

\section{Transfection}

Western blot analysis showed that stable transfection with plasmid carrying siRNA with homology to the p38 MAPK resulted in two clones with undetectable or very low expression of the p38 MAPK compared to controls transfected with inert plasmid (Fig. 1A and B). Both these clones (Min-p38 MAPK1 and Min-p38 MAPK2) were used in all subsequent experimentations. Several other clones that survived the blasticidin selection did not show a significant reduction in the p38 MAPK expression and, therefore, were not used for further studies. Two controls that were stably transfected with plasmid carrying non-interfering RNA showed characteristics identical to those of intact MCF-7 cells in terms of a net increase in cell number, proliferation, and apoptosis rates of untreated and hormonally treated cells. Therefore, one representative control is presented in subsequent studies except when otherwise indicated.
Growth characteristics of the Min-p38 MAPK cells

Figure 2 shows that the absence of p38 MAPK expression affected overall growth rate of the Min-p38 MAPK cells. In particular, when they were treated with $\mathrm{E}_{2}$ for 6 days, they showed a significantly higher net increase in cell number compared to controls, whereas their increase in cell number was decreased compared to control cells when they were treated with human GH plus EGF. In fact, although a slight increase in cell number was seen after GH plus EGF treatment, this increase was not significantly different from that seen in untreated Min-p38 MAPK cells. Although the net increase in cell number of the Min-p38 MAPK cells was higher than that of controls after $\mathrm{E}_{2}$ administration, this was not reflected in an increase in cell proliferation after a shortterm culture in that when the Min-p38 MAPK cells were treated with $\mathrm{E}_{2}$ for $18 \mathrm{~h}$, their BrdU uptake was actually lower than that of controls (Fig. 3). These results indicate either that more than $18 \mathrm{~h}$ were needed for the Min-p38 MAPK cells to significantly enhance their proliferation rate over controls, or that their apoptosis rate was reduced compared to controls. Indeed, when we measured the apoptotic rate of the Min-p38 MAPK cells, they did show a significant reduction in programed cell death compared to controls (Fig. 4). Therefore, it is likely that the main cause for the net increased cell number of the Min-p38 MAPK cells after $E_{2}$ stimulation was a decrease in cell death but not increased proliferation. However, apoptosis rate was not affected by the $E_{2}$ treatment in either Min-p38 MAPK cells or controls, but it was probably the reduction in the basal apoptosis rate seen in the

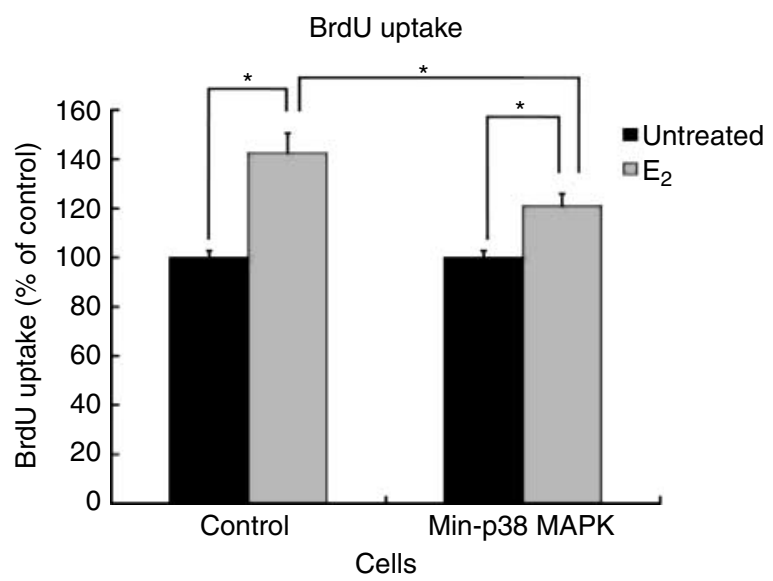

Figure 3 Proliferation rate of the MCF-7 cells expressing a low level of p38 mitogen-activated protein kinase (Min-p38 MAPK1, 2) and controls. The cells were plated onto 96-well plates in DMEM/F12 medium with $10 \%$ FBS and incubated overnight. The following day, the medium was changed to serum free, and the cells were incubated for an additional $24 \mathrm{~h}$. The cells were then treated with $100 \mathrm{nM} 17 \beta$-estradiol $\left(E_{2}\right)$ or vehicle (untreated) and incubated overnight. Fresh media containing $10 \mu \mathrm{M}$ 5-bromo-2'-deoxyuridine $(\mathrm{BrdU})$, treatment and control were then added, and the incubation continued for an additional $90 \mathrm{~min}$ when cultures were terminated and BrdU uptake was determined. Each bar represents mean \pm S.E.M. for eight replicate wells. ${ }^{*}$ Significantly different, $P<0 \cdot 05$. 


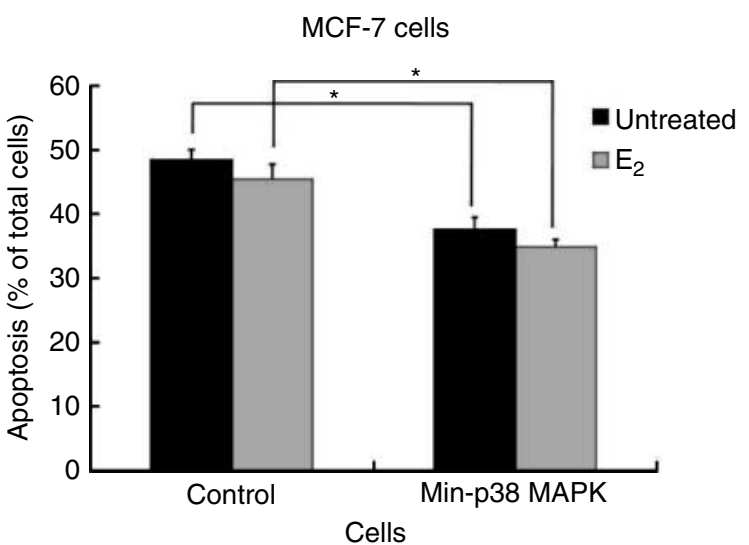

Figure 4 The rate of apoptosis was measured using an ELISA specific for a neo-epitope on cytokeratin 18 that is exposed after caspase cleavage. Min-p38 MAPK1, 2 and controls were plated onto 96-well plates in DMEM/F12 medium containing 10\% FBS and incubated overnight. The cells were then serum-starved for an additional $24 \mathrm{~h}$ and then treated overnight with $100 \mathrm{nM} 17 \beta$-estradiol $\left(E_{2}\right), 60 \mu \mathrm{M}$ roscovitine, or vehicle (untreated). Experiments were terminated by lysing the cells with $10 \%$ NP-40, final concentration was $0 \cdot 5 \%$, and the cell lysate was then diluted and assayed according to the manufacturer's directions. Each bar represents mean \pm S.E.M. for four to five replicate wells. ${ }^{*}$ Significantly different, $P<0 \cdot 05$.

Min-p38 MAPK cells compared to controls that allowed a faster accumulative increase in the total cell number over time for the Min-p38 MAPK cells.

\section{Expression of $E R \alpha, E R \beta, P R$, and cyclin $D 1$}

Western blot analyses were used to investigate whether the increased response of the Min-p38 MAPK cells to $E_{2}$ was associated with changes in the expression of the ERs. These analyses revealed that ER $\alpha$ expression in the Min-p38 MAPK cells was significantly enhanced when compared with controls, but the opposite was found for $\operatorname{ER} \beta$, where the expression was barely detectable in Min-p38 MAPK cells (Fig. 5A and B). Concomitant with the increase in ER $\alpha$ expression was an increase in the A-form of the PR, but the B-form of the PR was found to be low in both controls and the Min-p38 MAPK cells (not shown). $E_{2}$ treatment enhanced slightly the PR-A expression in both Min-p38 MAPK cells and controls (Fig. 6A and B). However, the increase was not statistically significant in either controls or Min-p38 MAPK cells. Surprisingly, the expression of cyclin $\mathrm{D} 1$, another $\mathrm{E}_{2}$-regulated gene, did not differ between the Min-p38 MAPK cells and controls (not shown).

\section{Activity of p53 tumor suppressor protein}

The p38 MAPK is an important regulator of the tumor suppressor protein p53 and is known to directly phosphorylate both serine 33 and serine 46 on the p53 protein (Bulavin et al. 1999, Takekawa et al. 2000). To investigate whether eliminating the expression of p38 MAPK would affect the activity of $\mathrm{p} 53$, the phosphorylation level of serine 46 was measured. As shown in Fig. 7A, the basal phosphorylation state of p53 was significantly reduced in both the Min-p38 MAPK cell lines compared to control. To determine whether the reduction in the phosphorylation levels of p53 in the Min-p38 MAPK cells was caused by diminished total expression of p53 protein in these cells, a western blot analysis was carried out. As shown in Fig. 7B, no significant difference was seen in the total $\mathrm{p} 53$ protein expression between controls and the Min-p38 MAPK cells.

\section{Tumorigenicity}

Immunodeficient mice were xenografted with both the Min-p38 MAPK cells and controls. Five animals were inoculated; one flank with the Min-p38 MAPK cells and the other with controls. Tumors developed in all cases at the inoculation sites for both the Min-p38 MAPK cells and controls (Fig. 8A). However, growth rate of the xenografted Min-p38 MAPK cells was approximately fourfold higher than that of the control cells (Fig. 8B and C). As shown in Fig. 8D, the expression of the p38 MAPK remained low in the xenografted Min-p38 MAPK cell compared to controls demonstrating that the Min-p38 MAPK cell maintained the expression of the siRNA to p38 MAPK after transplantation.

\section{Discussion}

Recently, we found that lowering the expression of the IGF-IR caused a reduction in ER $\alpha$ expression but increased the levels of ER $\beta$ and a concomitant decrease in growth of ER-positive breast cancer cells (Mendoza et al. 2011).
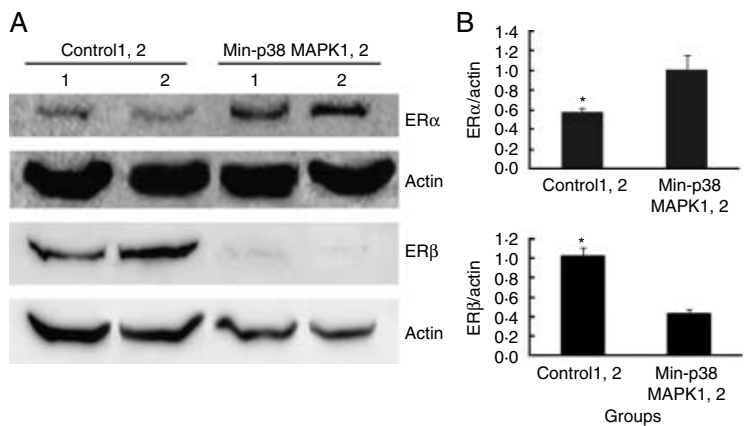

Figure 5 Western blot analysis showing basal expressions of the estrogen receptor $\alpha(E R \alpha)$ and ER $\beta$ in cloned MCF-7 cells stably transfected with small interfering RNA (siRNA) to p38 MAPK (Min-p38 MAPK) and controls. $\beta$-Actin was used as an internal standard. Cells were plated onto $60 \mathrm{~mm}$ culture dishes in DMEM/F12 medium containing 10\% FBS and cultured for $24 \mathrm{~h}$, followed by serum starvation for an additional $24 \mathrm{~h}$, when cells were harvested and lysed, and total protein was extracted and measured using BCA assay, followed by SDS-PAGE using $60 \mu \mathrm{g}$ total protein per lane and western blotted $(\mathrm{A})$. The results from the western blotting were quantified using densitometry and are presented as means \pm S.E.M. of six (ER $\alpha$ for both groups) and four (ER $\beta$ for both groups) replicates. Asterisk indicates significant difference between controls and Min-p38 MAPK cells, $P<0 \cdot 05$ (B). 

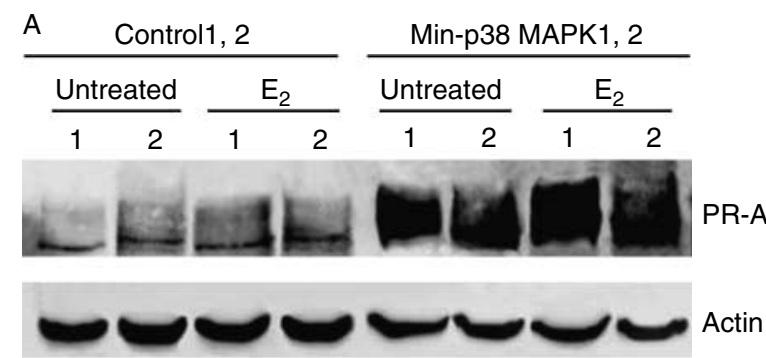

B

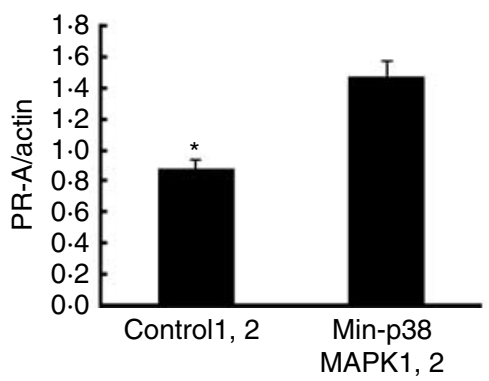

Figure 6 Western blot analysis showing expressions of the progesterone receptor $\mathrm{A}$ (PR-A) in cloned MCF-7 cells stably transfected with small interfering RNA (siRNA) to p38 MAPK (Min-p38 MAPK) and controls. $\beta$-Actin was used as an internal standard. Cells were plated onto $60 \mathrm{~mm}$ culture dishes in DMEM/F12 medium containing $10 \% \mathrm{FBS}$ and cultured for $24 \mathrm{~h}$. The cells were then serum-starved overnight and then treated with $100 \mathrm{nM}$ $17 \beta$-estradiol $\left(\mathrm{E}_{2}\right)$ or vehicle (untreated) and incubated for an additional $24 \mathrm{~h}$, when cells were harvested and lysed, and total protein extracted and measured using BCA assay. Samples were then subjected to SDS-PAGE using $60 \mu \mathrm{g}$ total protein per lane and western blotted (A). The results from the western blotting were quantified using densitometry and are shown as means \pm S.E.M. of four replicates for both groups. Asterisk indicates significant difference between controls and Min-p38 MAPK cells, $P<0 \cdot 05$ (B).

An increase in the level of ER $\beta$ has frequently been associated with an increased rate of apoptosis in different tissues (reviewed in Zhao et al. (2008)). We reasoned that this shift in the ER $\alpha: E R \beta$ ratio might be increasing the apoptosis rate of the cells and thereby decreasing their overall growth rate. Indeed, when we investigated this possibility, we found that programed cell death was significantly increased in the cells with low IGFIR expression and we also obtained evidence that this increased cell death was mediated through activation of the p38 MAPK (Mendoza et al. 2011). Here, we continue to study the involvement of p38 MAPK in cell death and survival. We generated cloned cell lines with significantly reduced expression of the p38 MAPK. In general, these cells displayed a phenotype completely opposite to that found in cells expressing a low level of IGF-IR in that they showed a higher $\operatorname{ER} \alpha: \operatorname{ER} \beta$ ratio, increased growth rate in response to $E_{2}$, decreased rate of apoptosis, and an increase in tumorigenicity when xenografted into immunodeficient mice. The role p38 MAPK plays in regulating cell growth is complex. It can be mitogenic in certain cell types and under certain physiological conditions, but it has also been known that activation of p38 MAPK can suppress cell growth and increase apoptosis, such as in different tumors (Ono \& Han 2000, Bulavin \& Fornace 2004, Thornton \& Rincon 2009). How, under normal circumstances, the activity of the p38 MAPK is regulated in the breast epithelia is not fully understood. We found, as mentioned above, that inhibiting the expression of IGF-IR causes a reduction in the expression of ER $\alpha$ and an increase in the levels of ER $\beta$, and treatment of these cells with $E_{2}$ causes a rapid phosphorylation of the p38 MAPK (Mendoza et al. 2011). Here, we show that eliminating the expression to the p38 MAPK causes a reduction in the expression of ER $\beta$ to barely detectable levels, while ER $\alpha$ expression was significantly enhanced compared to control cells. Both these results suggest that the ERs are essential

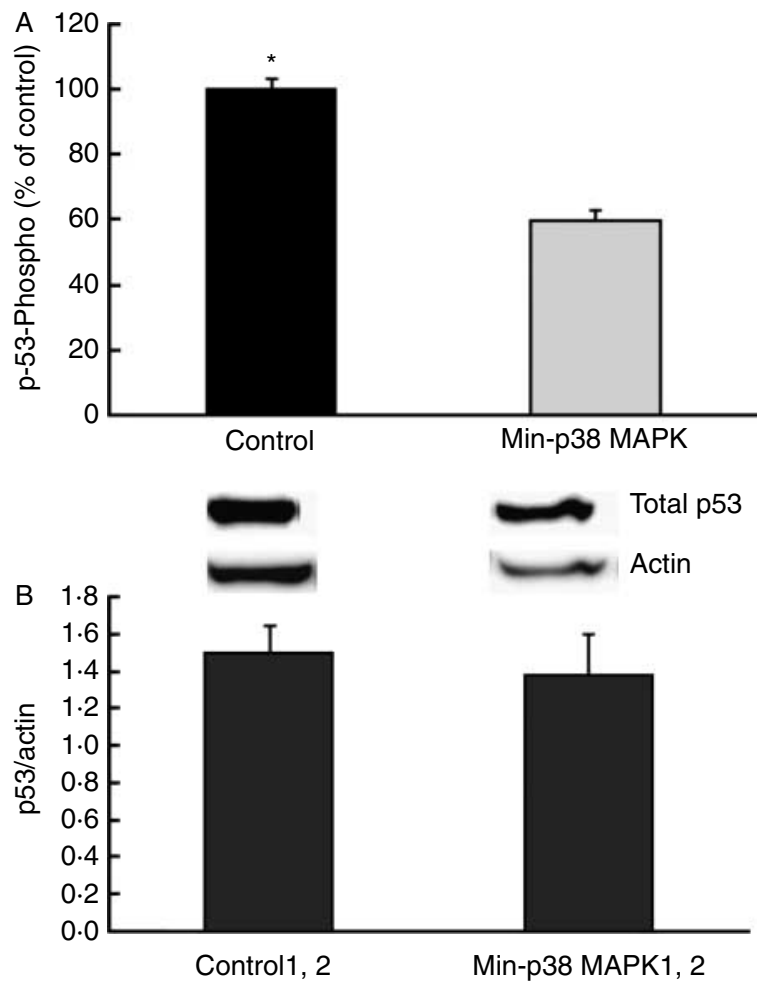

Figure 7 The basal activity (phosphorylation) of the p53 tumor suppressor protein was measured using ELISA. The Min-p38 MAPK1, 2 and control cells were plated onto $60 \mathrm{~mm}$ culture plates in $10 \%$ FBS and incubated overnight, followed by $24 \mathrm{~h}$ serum starvation. Medium was then removed, and fresh serum-free medium was applied and incubation continued for an additional $10 \mathrm{~min}$, when the cells were washed and harvested by scraping in ice-cold PBS. After centrifugation for $5 \mathrm{~min}$, the cells were lysed and the assays were carried out. Total protein concentrations of the cell lysates were used for normalizing the assay results. Each bar represents the mean \pm s.E.M. of three replicate plates for each cell line. * Significant difference between Min-p38 MAPK1, 2 and controls, $P<0 \cdot 05$. The results for the two Min-p38 MAPK cell lines were combined for the statistical analysis and are presented combined in the graph (A). The total protein expression levels of p53 were determined using western blot analysis and densitometric quantification. The results are expressed as p53/ $\beta$-actin ratio. Each bar represents the mean \pm S.E.M. of four replicates for both groups (B). 

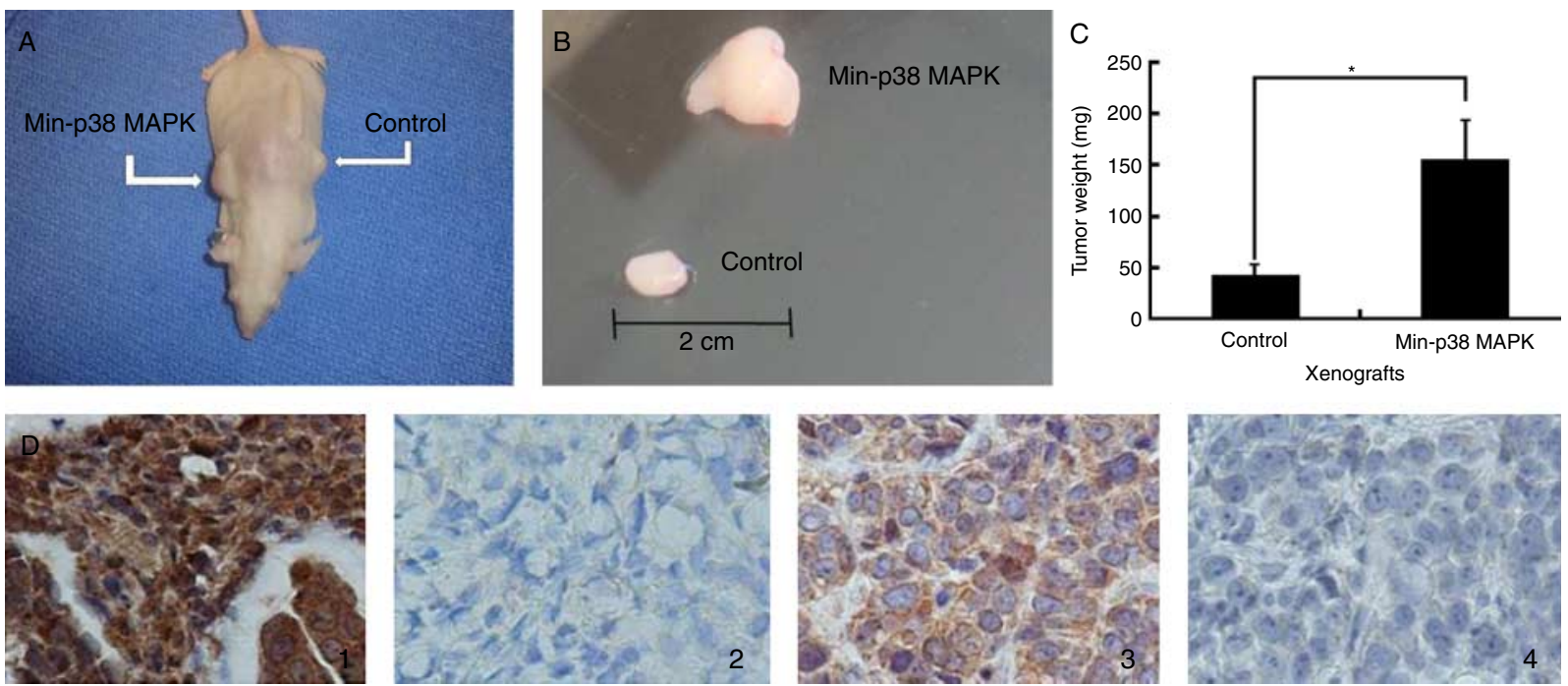

Figure 8 The tumorigenicity of MCF-7 cells lacking p38 MAPK (Min-p38 MAPK) was studied by s.c. injecting Min-p38 MAPK cells into immunodeficient mice fitted with silastic capsule containing $30 \mu \mathrm{g} 17 \beta$-estradiol $\left(\mathrm{E}_{2}\right)$. Each animal was injected with $1 \times 10^{7} \mathrm{Min}-\mathrm{p} 38$ MAPK cells in BD Matrigel $(150 \mu \mathrm{l})$ and control cells in the same medium. The animals received Min-p38 MAPK cells in one flank and control cells with scrambled siRNA vector in the other flank, i.e. each animal was inoculated with both Min-p38 MAPK cells and control cells with scrambled siRNA vector. Tumor size was measured weekly for 4 weeks beginning 1 month after inoculation. Two months after inoculation, animals were killed, and tumors were harvested and weighed. Photograph showing a mouse bearing Min-p38 xenograft and control cells with scrambled siRNA vector (A). Photograph showing xenografts of Min-p38 MAPK and control cells with scrambled siRNA vector at the time of harvest (B). Bar graph showing average xenograft weight for Min-p38 MAPK and control cells with scrambled siRNA vector after 8 weeks of growth. Each bar represents the mean \pm s.E.M. of tumors from five animals. Asterisk indicates significant difference between control cells with scrambled siRNA vector and Min-p38 MAPK cells, $P<0 \cdot 05$ (C). Microphotograph showing immunohistochemical detection of p38 MAPK in tumor xenografts obtained from immunodeficient mice. 1) Positive immunostaining for p38 MAPK in control tumor with scrambled siRNA vector. 2) Section from the same control tumor with scrambled siRNA vector where the primary antibody was omitted (negative control). 3) Immunostaining for p38 MAPK of Min-p38 MAPK tumor. 4) Negative control (primary antibody omitted) for Min-p38 MAPK tumor. Note the weak immunostaining for p38 MAPK in the Min-p38 MAPK xenograft compared to the control xenograft tumors with scrambled siRNA vector (D). Full colour version of this figure available via http://dx.doi. org/10.1677/JOE-10-0237.

regulators of the p38 MAPK, and it appears that ER $\beta$ is the active player in that regulation. We know that ER $\beta$ will activate the p38 MAPK in the absence of ER $\alpha$ (Caiazza et al. 2007). In addition, evidence supports a dominant role of ER $\beta$ in the interactions of the two ER isoforms (Pettersson et al. 2000, Liu et al. 2002). However, it has also been shown that $\mathrm{ER} \alpha$ is capable of activating the $\mathrm{p} 38$ MAPK in complete absence of ER $\beta$ (Lee \& Bai 2002, Acconcia et al. 2005), and p38 MAPK phosphorylates ER $\alpha$ at threonine-311 $\left(\mathrm{Thr}^{311}\right)$, demonstrating reciprocal interactions between p38 MAPK and ER $\alpha$ (Lee \& Bai 2002). Therefore, our understanding of how the ERs regulate p38 activity is still incomplete. Nonetheless, increasing evidence now supports a significant role for ER $\beta$ in enhancing cell apoptosis. For example, transfecting T47D ER-positive breast cancer cells with the ER $\beta$ inhibits cell proliferation after $\mathrm{E}_{2}$ administration (Strom et al. 2004), and ER $\beta$ has been found to suppress the expressions of cyclin D1 and other growth regulatory genes in T47D breast cancer cells and HeLa cells (Liu et al. 2002, Strom et al. 2004). Also, transfecting MCF-7 breast cancer cells with ER $\beta$ increases the efficacy of anti-estrogenic compounds in culture (Hodges-Gallagher et al. 2008). In addition, preinvasive, proliferating breast cancers show a reduction in the expression of ER $\beta$ indicating a loss of growth inhibition (Roger et al. 2001), and reduced levels of ER $\beta$ are associated with the anti-estrogen resistance in breast cancers (Hopp et al. 2004). We mentioned above that both $\operatorname{ER} \alpha$ and $\operatorname{ER} \beta$ are capable of activating p38 MAPK. However, the effects of this p38 MAPK activation appear to be opposite. When Lee $\&$ Bai (2002) demonstrated that ER $\alpha$ causes phosphorylation of p38 MAPK and, in turn, p38 MAPK-phosphorylated $\mathrm{Thr}^{311}$ on the $\mathrm{ER} \alpha$, they associated this activity with an increase in cell growth, whereas ER $\beta$ activation of the p38 MAPK is associated with an increase in the rate of apoptosis (Zhao et al. 2008), and, generally, most studies have shown the opposite effects of the two isoforms of the ERs on gene expression and cell growth in most cell types (Liu et al. 2002, Lindberg et al. 2003, Acconcia et al. 2005, Chang et al. 2006). Our results agree with these previous findings in that largely eliminating the expression of $\mathrm{p} 38$ MAPK causes a significant increase in growth of these cells in culture when treated with $E_{2}$, and xenografting the cells into immunodeficient mice increased their tumorigenicity. Previously, we had demonstrated that an increase in p38 MAPK activity through a reduction in IGF-IR/ER $\alpha$ expression reduced growth rate in response to $\mathrm{E}_{2}$ (Mendoza et al. 2011). How the two ERs are 
causing phosphorylation of the p38 MAPK with opposite effects on cell growth is not understood. However, it is worth noting that p38 MAPK activation can be achieved through different signaling pathways (Ge et al. 2002, 2003, Kang et al. 2006, Lu et al. 2006) and, therefore, the two ERs could be utilizing different signaling for the activation of p38 MAPK resulting in opposite biological effects. This is certainly possible, particularly when results from experiments with different cell types are compared.

How p38 MAPK is increasing the apoptotic rate of the cells is not known. We found that the phosphorylation of the tumor suppressor protein p53 was significantly decreased in cells with inactive p38 MAPK, and previously we had shown that an increase in p38 MAPK activity was associated with an increase in p53 phosphorylation. It has been shown that p53 is a substrate for p38 MAPK (Bulavin et al. 1999, Takekawa et al. 2000), and we suggest a causative relationship between p38 MAPK activity, p53 phosphorylation, and rate of apoptosis in breast cancer cells. Recently, Chen et al. (2009) showed that inhibiting p38 MAPK activity in MDA-MB-468 and MDAMB-231, both breast cancer cells with mutated p53 gene, inhibited growth of these cells, whereas MCF-7 cells with intact p53 gene (Casey et al. 1991) were not affected. They suggested that the effects of p38 MAPK in regulating growth of breast cancer depended on whether the tumors expressed intact or mutated forms of p53, with p38 MAPK predominantly enhancing apoptosis in cells with functional p53, but causing growth stimulation in cells lacking p53 function. Our results are in line with this conclusion and implicate the ERs as major players in this regulation.

\section{Declaration of interest}

The authors declare that there is no conflict of interest that could be perceived as prejudicing the impartiality of the research reported.

\section{Funding}

This research was generously supported by grants from Laura W Bush Institute for Women's Health-Permian Basin and National Institutes of Health/National Cancer Institute R03CA128067 and R03CA128067-02S1 awarded to GT.

\section{Acknowledgements}

We thank Edward Jin for providing many of the antibodies for this study and for useful discussions.

\section{References}

Acconcia F, Totta P, Ogawa S, Cardillo I, Inoue S, Leone S, Trentalance A, Muramatsu M \& Marino M 2005 Survival versus apoptotic $17 \beta$-estradiol effect: role of ER $\alpha$ and ER $\beta$ activated non-genomic signaling. Journal of Cellular Physiology 203 195-201. (doi:10.1002/jcp.20219)

Bulavin DV \& Fornace AJ Jr 2004 p38 MAP kinase's emerging role as a tumor suppressor. Advances in Cancer Research 92 95-118. (doi:10.1016/S0065230X(04)92005-2)
Bulavin DV, Saito S, Hollander MC, Sakaguchi K, Anderson CW, Appella E \& Fornace A Jr 1999 Phosphorylation of human p53 by p38 kinase coordinates N-terminal phosphorylation and apoptosis in response to UV radiation. EMBO Journal 18 6845-6854. (doi:10.1093/emboj/18.23.6845)

Caiazza F, Galluzzo P, Lorenzetti S \& Marino M 2007 17ß-Estradiol induces ER $\beta$ up-regulation via p38/MAPK activation in colon cancer cells. Biochemical and Biophysical Research Communications 359 102-107. (doi:10.1016/j.bbrc.2007.05.059)

Casey G, Lo-Hsueh M, Lopez ME, Vogelstein B \& Stanbridge EJ 1991 Growth suppression of human breast cancer cells by the introduction of a wild-type p53 gene. Oncogene 6 1791-1797.

Chang EC, Frasor J, Komm B \& Katzenellenbogen BS 2006 Impact of estrogen receptor $\beta$ on gene networks regulated by estrogen receptor $\alpha$ in breast cancer cells. Endocrinology 147 4831-4842. (doi:10.1210/en. 2006-0563)

Chen L, Mayer JA, Krisko TI, Speers CW, Wang T, Hilsenbeck SG \& Brown PH 2009 Inhibition of the p38 kinase suppresses the proliferation of human ER-negative breast cancer cells. Cancer Research 69 8853-8861. (doi:10.1158/0008-5472.CAN-09-1636)

Fagan DH \& Yee D 2008 Crosstalk between IGF1R and estrogen receptor signaling in breast cancer. Journal of Mammary Gland Biology and Neoplasia 13 423-429. (doi:10.1007/s10911-008-9098-0)

Ge B, Gram H, Di Padova F, Huang B, New L, Tlevitch RJ, Luo Y \& Han J 2002 MAPKK-independent activation of p38 $\alpha$ mediated by TAB1dependent autophosphorylation of p38 $\alpha$. Science 295 1291-1294. (doi:10. 1126/science.1067289)

Ge B, Xiong X, Jing Q, Mosley JL, Filose A, Bian D, Huang S \& Han J 2003 Tab1 $\beta$ (transforming growth factor- $\beta$-activated protein kinase 1-binding protein $1 \beta$ ), a novel splicing variant of TAB1 that interacts with $\mathrm{p} 38 \alpha$ but not TAK1. Journal of Biological Chemistry 278 2286-2293. (doi:10.1074/jbc. M210918200)

Hagg M, Biven K, Ueno T, Rydlander L, Bjorklund P, Wiman KG, Shoshan M \& Linder S 2002 A novel high-through-put assay for screening of pro-apoptotic drugs. Investigational New Drugs $20253-259$. (doi:10.1023/A:1016249728664)

Hall JM \& McDonnell DP 1999 The estrogen receptor $\beta$-isoform (ER $\beta$ ) of the human estrogen receptor modulates $\mathrm{ER} \alpha$ transcriptional activity and is a key regulator of the cellular response to estrogens and antiestrogens. Endocrinology 140 5566-5578. (doi:10.1210/en.140.12.5566)

Hinegardner RT 1971 An improved fluorometric assay for DNA. Analytical Biochemistry 39 197-201. (doi:10.1016/0003-2697(71)90476-3)

Hodges-Gallagher L, Valentine CD, El Bader S \& Kushner PJ 2008 Estrogen receptor beta increases the efficacy of antiestrogens by effects on apoptosis and cell cycling in breast cancer cells. Breast Cancer Research and Treatment 109 241-250. (doi:10.1007/s10549-007-9640-6)

Hopp TA, Weiss HL, Parra IS, Cui Y, Osborne CK \& Fuqua SAW 2004 Low levels of estrogen receptor $\beta$ protein predict resistance to tamoxifen therapy in breast cancer. Clinical Cancer Research 10 7490-7499. (doi:10.1158/10780432.CCR-04-1114)

Kang YJ, Seit-Nebi A, Davis RJ \& Han J 2006 Multiple activation mechanisms of p38 $\alpha$ mitogen-activated protein kinase. Journal of Biological Chemistry 281 26225-26234. (doi:10.1074/jbc.M606800200)

Kleinberg DL \& Ruan W 2008 IGF-I, GH, and sex steroid effects in normal mammary gland development. Journal of Mammary Gland Biology and Neoplasia 13 353-360. (doi:10.1007/s10911-008-9103-7)

Lee H \& Bai W 2002 Regulation of estrogen receptor nuclear export by ligand-induced and p38-medicate receptor phosphorylation. Molecular and Cellular Biology 22 5835-5845. (doi:10.1128/MCB.22.16.5835-5845. 2002)

Lindberg MK, Moverare S, Skrtic S, Gao H, Dahlman-Wright K, Gustafsson J-A \& Ohlsson C 2003 Estrogen receptor (ER)- $\beta$ reduces ER $\alpha$-regulated gene transcription, supporting a "Ying Yang" relationship between ER $\alpha$ and ER $\beta$ in mice. Molecular Endocrinology 17 203-208. (doi:10.1210/me. 2002-0206)

Liu Y, Lehar S, Corvi C, Payne G \& O'Connor R 1998 Expression of the insulin-like growth factor I receptor $\mathrm{C}$ terminus as a myristylated protein leads to induction of apoptosis in tumor cells. Cancer Research 58 570-576. 
Liu M-M, Albanese C, Anderson CM, Hilty K, Webb P, Uht RM, Price RH Jr, Pestell RG \& Kushner PJ 2002 Opposing action of estrogen receptors $\alpha$ and $\beta$ on cyclin D1 gene expression. Journal of Biological Chemistry 277 24353-24360. (doi:10.1074/jbc.M201829200)

Lu G, Kang YJ, Han J, Herschman HR, Stefani E \& Wang Y 2006 TAB-1 modulates intracellular localization of p38 MAP kinase and downstream signaling. Journal of Biological Chemistry 281 6087-6095. (doi:10.1074/jbc. M507610200)

Mendoza RA, Enriquez MI, Mejia SM, Moody EE \& Thordarson G 2011 Interactions between IGF-I, estrogen receptor- $\alpha(\mathrm{ER} \alpha)$, and ER $\beta$ in regulating growth/apoptosis of MCF-7 human breast cancer cells. Journal of Endocrinology 208 1-9. (doi:10.1677/JOE-10-0235)

Ono K \& Han J 2000 The p38 signal transduction pathway activation and function. Cellular Signalling 12 1-13. (doi:10.1016/S0898-6568(99)00071-6)

Pedram A, Razandi M \& Levin ER 2006 Nature of functional estrogen receptors at the plasma membrane. Molecular Endocrinology 20 1996-2009. (doi:10.1210/me.2005-0525)

Pettersson K, Delaunay F \& Gustafsson J-A 2000 Estrogen receptor $\beta$ acts as a dominant regulator of estrogen signaling. Oncogene 19 4970-4978. (doi:10. 1038/sj.onc.1203828)

Razandi M, Pedram A, Greene GL \& Levin ER 1999 Cell membrane and nuclear estrogen receptors (ERs) originate from a single transcript: studies of $\operatorname{ER} \alpha$ and ER $\beta$ expressed in Chinese hamster ovary cells. Molecular Endocrinology 13 307-319. (doi:10.1210/me.13.2.307)

Razandi M, Pedram A, Merchenthaler I, Greene GL \& Levin ER 2004 Plasma membrane estrogen receptors exist and functions as dimers. Molecular Endocrinology 18 2854-2865. (doi:10.1210/me.2004-0115)

Roger P, Sahla ME, Makela S, Gustafsson J-A, Baldet P \& Rochefort H 2001 Decreased expression of estrogen receptor $\beta$ protein in proliferative preinvasive mammary tumors. Cancer Research 61 2537-2541.

Schutte B, Henfling M, Kolgen W, Bouman M, Meex S, Leers MPG, Nap M, Bjorklund V, Bjorklund P, Bjorklund B et al. 2004 Keratin 8/18 breakdown and reorganization during apoptosis. Experimental Cell Research 297 11-26. (doi:10.1016/j.yexcr.2004.02.019)
Song RX-D \& Santen RJ 2003 Apoptotic action of estrogen. Apoptosis 8 55-60. (doi:10.1023/A:1021649019025)

Song RX-D, Zhang Z, Chen Y, Bao Y \& Santen RJ 2007 Estrogen signaling via a linear pathway involving insulin-like growth factor I receptor, matrix metalloproteinases, and epidermal growth factor receptor to activate mitogen-activated protein kinase in MCF-7 breast cancer cells. Endocrinology 148 4091-4101. (doi:10.1210/en.2007-0240)

Strom A, Hartman J, Foster JS, Kietz S, Wimalasena J \& Gustafsson JA 2004 Estrogen receptor $\beta$ inhibits $17 \beta$-estradiol-stimulated proliferation of the breast cancer cell line T47D. PNAS 101 1566-1571. (doi:10.1073/pnas. 0308319100)

Takekawa M, Adachi M, Nakahata A, Nakayama I, Itoh F, Tsukuda H, Taya Y \& Imai K 2000 p53-induced Wip1 phosphatase mediates a negative feedback regulation of p38 MAPK-p53 signaling in response to UV radiation. EMBO Journal 19 6517-6526. (doi:10.1093/emboj/19.23.6517)

Thordarson G, Slusher N, Leong H, Ochoa D, Rajkumar L, Guzman R, Nandi S \& Talamantes F 2004 Insulin-like growth factor (IGF) I obliterates the pregnancy-associated protection against mammary carcinogenesis in rats: evidence that IGF-I enhances cancer progression through estrogen receptor- $\alpha$ activation via the mitogen-activated protein kinase pathway. Breast Cancer Research 6 R423-R436. (doi:10.1186/bcr812)

Thornton TM \& Rincon M 2009 Non-classical p38 map kinase functions: cell cycle checkpoints and survival. International Journal of Biological Sciences $\mathbf{5}$ 44-52.

Zhao C, Dahlman-Wright K \& Gustafsson J-A 2008 Estrogen receptor $\beta$ : an overview and update. Nuclear Receptor Signaling 6 e003. (doi:10.1621/nrs. 06003)

Received in final form 19 October 2010

Accepted 25 October 2010

Made available online as an Accepted Preprint 25 October 2010 